\title{
Ultra-thin anodized aluminium dielectric films: the effect of citric acid concentration and low-voltage electronic applications \\ DOI:
}

10.1088/1361-6528/ab7fd1

\section{Document Version}

Accepted author manuscript

Link to publication record in Manchester Research Explorer

Citation for published version (APA):

Sagar, S., Mohammadian, N., Park, S., Majewski, L. A., \& Das, B. C. (2020). Ultra-thin anodized aluminium dielectric films: the effect of citric acid concentration and low-voltage electronic applications. Nanotechnology. https://doi.org/10.1088/1361-6528/ab7fd1

\section{Published in:}

Nanotechnology

\section{Citing this paper}

Please note that where the full-text provided on Manchester Research Explorer is the Author Accepted Manuscript or Proof version this may differ from the final Published version. If citing, it is advised that you check and use the publisher's definitive version.

\section{General rights}

Copyright and moral rights for the publications made accessible in the Research Explorer are retained by the authors and/or other copyright owners and it is a condition of accessing publications that users recognise and abide by the legal requirements associated with these rights.

\section{Takedown policy}

If you believe that this document breaches copyright please refer to the University of Manchester's Takedown Procedures [http://man.ac.uk/04Y6Bo] or contact uml.scholarlycommunications@manchester.ac.uk providing relevant details, so we can investigate your claim.

\section{OPEN ACCESS}


ACCEPTED MANUSCRIPT

\section{Ultra-thin anodized aluminium dielectric films: the effect of citric acid concentration and low-voltage electronic applications}

To cite this article before publication: Srikrishna Sagar et al 2020 Nanotechnology in press https://doi.org/10.1088/1361-6528/ab7fd1

\section{Manuscript version: Accepted Manuscript}

Accepted Manuscript is "the version of the article accepted for publication including all changes made as a result of the peer review process, and which may also include the addition to the article by IOP Publishing of a header, an article ID, a cover sheet and/or an 'Accepted Manuscript' watermark, but excluding any other editing, typesetting or other changes made by IOP Publishing and/or its licensors"

This Accepted Manuscript is @ 2020 IOP Publishing Ltd.

During the embargo period (the 12 month period from the publication of the Version of Record of this article), the Accepted Manuscript is fully protected by copyright and cannot be reused or reposted elsewhere.

As the Version of Record of this article is going to be / has been published on a subscription basis, this Accepted Manuscript is available for reuse under a CC BY-NC-ND 3.0 licence after the 12 month embargo period.

After the embargo period, everyone is permitted to use copy and redistribute this article for non-commercial purposes only, provided that they adhere to all the terms of the licence https://creativecommons.org/licences/by-nc-nd/3.0

Although reasonable endeavours have been taken to obtain all necessary permissions from third parties to include their copyrighted content within this article, their full citation and copyright line may not be present in this Accepted Manuscript version. Before using any content from this article, please refer to the Version of Record on IOPscience once published for full citation and copyright details, as permissions will likely be required. All third party content is fully copyright protected, unless specifically stated otherwise in the figure caption in the Version of Record.

View the article online for updates and enhancements. 


\section{Ultra-thin Anodized Aluminium Dielectric Films: The Effect of Citric Acid}

\section{Concentration and Low-Voltage Electronic Applications}

Srikrishna Sagar ${ }^{1}$, Navid Mohammadian ${ }^{2}$, Seonghyun Park ${ }^{2}$, Leszek A. Majewski ${ }^{2}$, and Bikas C.

$\operatorname{Das}^{1, *}$

${ }^{1}$ Emerging Nanoelectronic Devices Research Laboratory (eNDR Lab), School of Physics, Indian Institute of Science Education and Research Thiruvananthapuram (IISER-TVM), Maruthamala PO, Vithura, Thiruvananthapuram 695551, Kerala, India.

${ }^{2}$ Department of Electrical and Electronic Engineering, The University of Manchester, Manchester M13 9PL, UK.

* Corresponding author

Email: bikas@iisertvm.ac.in

ORCID ID

Bikas C. Das: 0000-0002-4750-0542

Leszek A Majewski: 0000-0001-6544-1286

Seonghyun Park: 0000-0003-3738-5883 


\begin{abstract}
Anodically oxidized, ultra-thin $(\mathrm{d}<10 \mathrm{~nm})$ aluminium films emerge as the dielectric of choice for low-cost thin film capacitors (TFCs), thin film transistors (TFTs), and bio- and chemical, sensors. In this work, the dielectric properties of ultra-thin aluminium oxide films grown by anodization in aqueous solutions of citric acid (CA) have been studied. It is observed that the electrolyte strength variation from $0.1 \mathrm{mM}$ to $1000 \mathrm{mM}$ has virtually no influence on the chemical composition, surface morphology and the dielectric properties of the fabricated alumina films. The anodized films are very smooth having RMS area roughness around $\sim 5$. This was further improved after deposition of $n$-octadecyltrichlorosilane (OTS) self-assembled monolayer (SAM) to $\sim 4 \AA$. Also, the elemental analysis using EDS and XPS unambiguously confirms that the obtained oxide films are amorphous, stoichiometric $\mathrm{Al}_{2} \mathrm{O}_{3}$ without any carbon contamination. The fabricated $\mathrm{Al} / \mathrm{Al}_{2} \mathrm{O}_{3} / \mathrm{Al} \mathrm{MIM}$ capacitors show almost ideal capacitor characteristics from $10 \mathrm{~Hz}$ to $100 \mathrm{kHz}$. It has been found that the OTS coating does not only improve the capacitor frequency response further but also reduces the leakage current through the dielectric layer by passivating reactive dangling bonds on the oxide surface. As a result of the favourable properties of the anodized $\mathrm{Al}_{2} \mathrm{O}_{3} / \mathrm{OTS}$ films, high-performance, low threshold voltage organic thin film transistors (OTFTs) operating below $1 \mathrm{~V}$ are demonstrated successfully.
\end{abstract}

Index Terms: Anodization; Ultra-thin aluminium oxide; Dielectrics; Impedance spectroscopy; Organic thin film transistor (OTFT). 


\section{INTRODUCTION}

Solution-deposited metal oxide dielectrics have drawn a lot of attention in recent years because they can be used in the fabrication of high performance thin film capacitors (TFCs) $(1,2)$, lowvoltage thin film transistors (TFTs) $(3,4)$, and bio- and chemical sensors $(5,6)$. However, the next generation of thin film electronic devices and systems will require reduced power consumption for which the development of dielectric materials that can be inexpensively deposited on large areas as ultra-thin films is urgently needed (7). Commonly, sophisticated deposition processes such as atomic layer deposition (ALD), pulsed laser deposition (PLD), chemical vapour deposition (CVD) and radio frequency $(\mathrm{RF})$ magnetron sputtering are used to grow pinhole and defects free ultrathin oxide layers but all of them depend on controlled environment and high temperature which significantly increases the processing costs. Recently, anodic oxidation (so-called anodization) has attracted a lot of attention because it is a low cost, solution-based deposition process that can be used to fabricate high quality, ultra-thin metal oxide films (8-10). Anodization is a self-limiting and self-healing process that gives pinhole-free, homogenous oxide layers that can be grown in ambient conditions using low cost set-ups and environmentally friendly chemicals (11).

Recently, high performance capacitors and TFTs (both organic and inorganic) operating at or below $1 \mathrm{~V}$ using ultra-thin, anodized metals as the gate dielectric have been demonstrated (3, 9 , 12). However, the material properties including composition and surface morphology of these ultra-thin oxide films have not been sufficiently studied yet. Among the metals that can be anodized, Al has proved to be the most popular because it is cheap and readily available on a wide range of substrates $(13,14)$. It has been shown that when processed in neutral electrolyte solutions (e.g. ammonium pentaborate, ammonium adipate, tartaric acid, etc.) the resulting barrier-type $\mathrm{Al}_{2} \mathrm{O}_{3}$ hás outstanding dielectric properties (15-17). To achieve high capacitance, high dielectric 
breakdown strength aluminium oxide films for thin film electronic devices, dilute solutions of citric acid (CA) in deionized (DI) water are commonly used $(18,19)$. However, very little is known about the influence of citric acid concentration on the dielectric properties of anodized Al films. Also, the presence of dangling bonds on the surface of metal oxides often results in poor adhesion of active materials and metal electrodes. Accordingly, unsatisfactory device performance is often obtained. Salinization using organometallic molecules, such as $n$-octadecyltrichlorosilane (OTS), which results in a monolayer on top of metal oxide surfaces, remains the most ubiquitous technique to passivate the dangling bonds and reduce the material surface roughness. However, the effect of this thin layer of organometallic molecules on the overall dielectric properties of the anodically oxidized, ultra-thin $\mathrm{Al}_{2} \mathrm{O}_{3} / \mathrm{OTS}$ insulator stacks has not been stúdied yet properly.

In this work, the dielectric properties of ultra-thin $(\mathrm{d}<10 \mathrm{~nm})$ anodized, barrier-type aluminium films grown in different citric acid concentrations are reported. It is shown that the chemical structure, surface morphology and the dielectric properties of the $\mathrm{Al}_{2} \mathrm{O}_{3}$ layers are not affected by the variation of citric acid concentrations from 0.1 to $1000 \mathrm{mM}$. This finding is in a strong contrast with the recently reported anodized aluminium and tantalum films where it was shown that electrolyte byproducts are incorporated into barrier-type anodic coatings $(20,21)$. The chemical composition and stoichiometry of the anodized Al films are studied using EDS and XPS, respectively. Both of them reveals that the obtained oxide films consist of stoichiometric $\mathrm{Al}_{2} \mathrm{O}_{3}$ without any carbon contamination. XRD confirms the amorphous nature of the anodized aluminium films. The fabricated capacitors using pristine $\mathrm{Al}_{2} \mathrm{O}_{3}$ show almost ideal capacitor behaviour in $10 \mathrm{~Hz}$ to $100 \mathrm{kHz}$ frequency range. When $\mathrm{Al}_{2} \mathrm{O}_{3}$ is passivated using OTS, a further improvement of the frequency response behaviour is observed between $100 \mathrm{mHz}$ to $100 \mathrm{kHz}$. The optimized TFTs using poly[2,5-(2-octyldodecyl)-3,6-diketonpyrrolopyrrole-alt-5,5-(2,5-di(thien- 
2-yl) thieno [3,2-b] thiophene)] (DPP-TTT) as the active channel layer exhibit highly reproducible characteristics with no current-voltage hysteresis, a saturation field-effect mobility $\mu_{\text {sat }} \approx 0.1$ $\mathrm{cm}^{2} \mathrm{~V}^{-1} \mathrm{~s}^{-1}$, threshold voltage of around $V_{\mathrm{TH}}=-0.41 \mathrm{~V}$, subthreshold swing $S S=155 \mathrm{mV} / \mathrm{dec}$, $I_{\mathrm{on}} / I_{\mathrm{off}}$ ratio $>10^{3}$, and leakage current $\left(I_{\mathrm{G}}\right)$ of approximately $100 \mathrm{pA}$ at $750 \mathrm{mV}$. The fabricated DPP-TTT TFTs show typical p-channel transistor behaviour demonstrating a high potential to use the optimized $\mathrm{Al}$ anodization process for practical organic TFT fabrication.

\section{EXPERIMENTAL DETAILS}

\subsection{Materials and chemicals}

Citric acid (CA, 99.5\%), n-octadecyltrichlorosilane (OTS), 2-propanol (IPA, 99.5\%), acetone (99.5\%), poly(methyl methacrylate) (PMMA, $\mathrm{M}_{\mathrm{w}}=97 \mathrm{k}$ ), 1,2-Dichlorobenzene (DCB, HPLC grade), and trichloroethylene (TCE, $\geq 99.5 \%$ ) were purchased from Sigma Aldrich/Merck India and were used as received without further purification. Poly[2,5-(2-octyldodecyl)-3,6diketonpyrrolopyrrole-alt-5,5-(2,5-di(thien-2-yl) thieno [3,2-b] thiophene)] (DPP-TTT) and ultrasmooth quartz coated glass substrates were purchased from Ossila Ltd., UK. 99.999\% pure $\mathrm{Al}$ and $\mathrm{Au}$ pellets were purchased from Kurt J. Lesker Company, UK. Cleaning of the substrates and preparation of the citric acid electrolyte solutions were done using high purity deionized (DI) water (18.2 M $\Omega \cdot c m$, Milli-Q Direct 8).

\subsection{Anodization and fabrication of devices}

Metal-insulator-metal (MIM) capacitors and organic thin film transistors (OTFTs) were fabricated on ultra-smooth, quartz coated glass substrates (Ossila Ltd., UK). First, the substrates were cleaned by sonication in acetone and IPA for 15 minutes each. The cleaning was repeated two times and then the/samples were dried using dry compressed air. Subsequently, the substrates were treated 
with UV-Ozone for 10 mins with emissivity maintained at $95 \%$ to remove any organic contaminants. Then, $100 \mathrm{~nm}$ thick Al electrodes were thermally deposited on the substrates through a metal shadow mask (Ossila Ltd., UK) using a PRO line PVD 75 system (Kurt J. Lesker $\mathrm{Co}, \mathrm{UK})$ at the working pressure $<2 \times 10^{-6}$ Torr. Afterwards, the substrates with the deposited $\mathrm{Al}$ films were immediately anodized according to the anodization procedure reported previously (22, 23). To investigate the influence of the citric acid concentration on the dielectric properties of the anodized $\mathrm{Al}$, the concentration of the citric acid in the electrolyte solution was varied ranging from $0.1 \mathrm{mM}$ to $1000 \mathrm{mM}$. The MIM capacitor samples were anodised to $5.0 \mathrm{~V}$ which results in the oxide thickness $(d)$ about $6.5 \mathrm{~nm}$ (24). Similarly, Al films for the OTFT devices were anodised to $2.3 \mathrm{~V}(d \sim 3 \mathrm{~nm})$. After anodization, the substrates were washed using high purity deionized (DI) water and dried using dry air. The prepared $\mathrm{Al} / \mathrm{Al}_{2} \mathrm{O}_{3}$ films were then annealed by keeping them on a hot plate at $120{ }^{\circ} \mathrm{C}$ for 5 minutes. To complete the devices fabrication for MIM capacitors, 50 $\mathrm{nm}$ thick Al was deposited through a metal shadow mask to serve as the top electrode over anodized aluminium films. For/OTS-treated MIM capacitors, before the top electrode deposition, a solution of $4.5 \mu 1$ OTS in $4 \mathrm{ml}$ of trichloroethylene (TCE) was spun at $3000 \mathrm{rpm}$ on top of the anodized aluminium films and dried in a vacuum oven for 20 minutes at $120{ }^{\circ} \mathrm{C}$. OTFTs with bottom-gate bottom-contact architecture were fabricated using $\mathrm{Al}_{2} \mathrm{O}_{3} / \mathrm{OTS}$ as the gate dielectric following similar ways reported earlier with changes as required $(17,18)$. Briefly, $50 \mathrm{~nm}$ thick $\mathrm{Au}$ contacts were deposited on the dielectric oxide layers through a metal shadow mask ( $\mathrm{L}=20 \mu \mathrm{m}$, $\mathrm{W}=1000 \mu \mathrm{m}$ ) (Ossila Ltd., UK) using e-beam PRO Line PVD 75 system (Kurt J. Lesker, UK) as source (S) and drain (D) electrodes. Then, a blend solution of DPP-TTT and PMMA in 1,2Dichlorobenzene (DCB) is prepared by dissolving $0.5 \mathrm{wt} \%$ of each separately and then blending them together with a 7:3 ratio under continuous stirring until completely mixed. Subsequently, 
the blend solution is spin coated at $2000 \mathrm{rpm}$ for 120 seconds on the substrates patterned with S$\mathrm{D}$ electrodes on the anodized $\mathrm{Al}$ pre-heated at $100^{\circ} \mathrm{C}$. To complete the OTFT fabrication, the deposited films were annealed at $100{ }^{\circ} \mathrm{C}$ for 1 hour under $\mathrm{N}_{2}$ environment.

\subsection{Characterization of thin films}

Scanning electron microscopy (SEM) images and energy dispersive X-ray (EDS) data were obtained using Apollo X SDD system coupled with a Nova Nano SEM450 system without the top Al coating. Atomic force microscope (AFM) (NanoWizard ${ }^{\circledR} 4$ NanoScience AFM, JPK, Germany) was used to record the surface topographic images of the samples. AFM imaging was performed in tapping mode at tip setpoint $788 \mathrm{mV}$ using silicon probes with force constant $40 \mathrm{~N} / \mathrm{m}$ and resonance frequency $327.9 \mathrm{kHz}$. JPK data prócessing software was utilized to analyze AFM data. X-ray photoelectron spectroscopy (XPS) data of glass and glass/Al/ $\mathrm{Al}_{2} \mathrm{O}_{3}$ films were recorded by versatile Omicron ESCA 2SR XPS system with Mg-K $\alpha$ X-ray source of energy $1253.6 \mathrm{eV}$.

\subsection{Electrical Characterizations of capacitors and TFTs}

Electrochemical Impedance Spectroscopy (EIS) data for all fabricated MIM capacitors were measured using Zahner Zennium Pro electrochemical workstation by connecting the working electrode at the bottom electrode. Typically, the frequency was swept from $100 \mathrm{mHz}$ to $100 \mathrm{kHz}$ with an AC bias amplitude set to $50 \mathrm{mV}$. Transistor characteristics were measured with Keithley 4200 SCS Source-Measure Unit and Janis ST-500 probe station at room temperature and a pressure $10^{-4}$ Torr. 


\section{RESULTS AND DISCUSSION}

Figure 1(a) shows anodization voltage $\left(V_{\mathrm{A}}\right)$ and current $\left(I_{\mathrm{A}}\right)$ vs. time $(t)$ profiles during the growth of aluminium oxide layer in $1 \mathrm{mM}$ aqueous solution of citric acid. As expected, the applied $/ I_{\mathrm{A}}$ remains constant until the desired $V_{\mathrm{A}}$ is reached and then it decreases exponentially (23). In order to see whether the concentration of CA influences the speed of aluminium oxide growth, anodization time $(t)$ vs. electrolyte concentration $\left(C_{\mathrm{E}}\right)$ for $V_{A}=5.0 \mathrm{~V}$ was studied. As shown in Figure 1(b), it appears that $t$ is almost independent on $C_{\mathrm{E}}$ for six different electrolyte concentrations, i.e. $0.1,1,10,100,500$ and $1000 \mathrm{mM}$. Therefore, we conclude that increasing the concentration of the citric acid by four orders of magnitude does not significantly affect the anodization time to grow ultra-thin, barrier type aluminium oxide layers. However, the anodization process involves the direct motion of aluminium and oxygen ions through the oxide layer during growth depending on the established electric field. The initial constant current regime (galvanostatic anodization regime) indicates that the formation of every oxide layer requires an increase of the potential drop to maintain the internal electric field in it constant keeping the anodization current $\left(I_{\mathrm{A}}\right)$ in the cell constant as appeared in Figure 1(a). As a result, the potential drop across the oxide layer is reached to the set anodization voltage $\left(V_{\mathrm{A}}\right)$ regime (potentiostatic anodization regime) after a while and the anodization current $\left(I_{\mathrm{A}}\right)$ starts dropping immediately which indicates the reduction of ion motion further involved with the oxide layer growth. This indicates the oxide layer growth is stopped completely and thickness of this anodized oxide layer is solely depends on the set anodization voltage (25). Assuming that the growth rate (so-called anodization ratio) of aluminium oxide in aqueous solutions of citric acid is $1.3 \mathrm{~nm} / \mathrm{V}$, the thickness of the oxide layers for all CA concentrations is the same and it is estimated to be approximately $6.5 \mathrm{~nm}$ (including the native oxide) $(22,23)$. To avoid the effect of film thickness variation on the 
dielectric behaviour of samples, maintaining the same oxide film thickness for all samples is crucial. Significantly, a sharp crossover between the galvanostatic and potentiostatic anodization regime confirms that the citric acid (CA) as electrolyte doesn't dissolve the native as well as anodized oxide layer during anodization process (25). As a control experiment, anodization of aluminium was also performed in high purity deionized water relying on the autoprotolysis of water. All other process parameters were identical including electrode separation of $20 \mathrm{~mm}$ as in the case of anodization in CA. It is observed that the set anodization voltage $\left(V_{\mathrm{A}}=5.0 \mathrm{~V}\right)$ was reached instantaneously and that the anodization current $\left(I_{\mathrm{A}}\right)$ started to decrease slowly from about $I_{\mathrm{A}}=6.5 \mu \mathrm{A}$ at the beginning of the anodization process to about $I_{\mathrm{A}}=4.0 \mu \mathrm{A}$ after 15 minutes of anodization as shown in the Supplementary Material Figure S1(a). Importantly, $I_{\mathrm{A}}$ started decreasing from much lower value than the set value $I_{\mathrm{A}}=15 \mu \mathrm{A}$. This clearly indicates that the applied $V_{\mathrm{A}}$ has entirely dropped across the high purity DI water medium due to its large resistance (> tens of $\mathrm{M} \Omega$ ). Therefore, we conclude that in order to grow oxide on aluminium films with native oxide layer using high purity DI water as the electrolyte either the anodization voltage has to be significantly increased (e.g. $V_{\mathrm{A}} \geq 100 \mathrm{~V}$ ) or the distance between the electrodes significantly decreased $(\mathrm{d} \leq \mathrm{mm})$. Also, since the thickness of the resulting films is controlled by the duration of anodization, the anodization in high purity DI water becomes difficult for thicker insulator films as anodization times increase considerably (23). In addition, the breakdown voltage of the fabricated $\mathrm{Al} / \mathrm{Al}_{2} \mathrm{O}_{3} / \mathrm{Al}$ MIM capacitors occurred with $V_{\mathrm{B}}$ between $1.5 \mathrm{~V}$ to $3.0 \mathrm{~V}$, as shown in the Supplementary Material Figure S1 (b). Again, this demonstrates that the anodization of Al in water strongly depends on anodization distance (i.e. conductivity/resistivity of the anodization solution) and is much more difficult to control/reproduce than the anodization of $\mathrm{Al}$ in aqueous solutions of CA. 
(a)

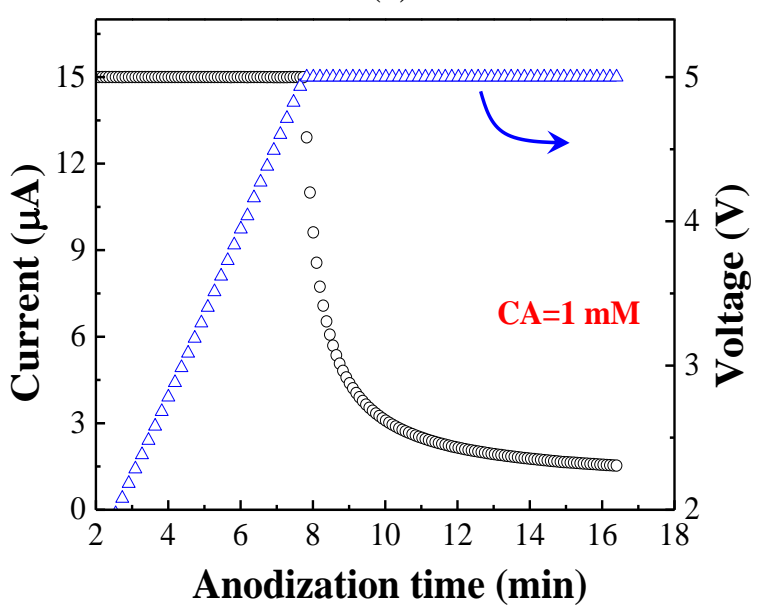

(b)

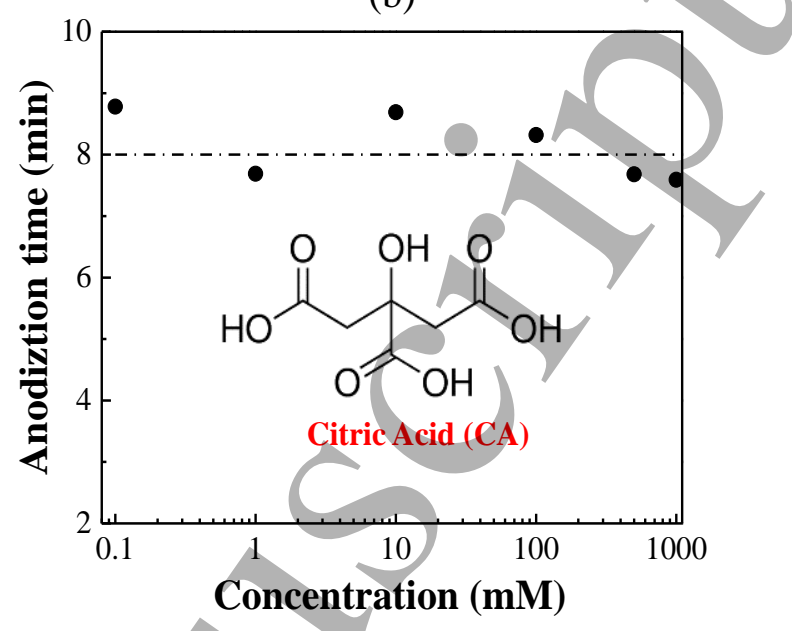

Figure 1. (a) Anodization current $\left(I_{\mathrm{A}}\right)$ and voltage $\left(V_{\mathrm{A}}\right)$ profile as a function of anodization time (t). (b) Anodization time vs. molar concentration of citric acid (CA) used for $\mathrm{V}_{\mathrm{A}}=5 \mathrm{~V}$ anodization process. Inset of Fig. 1(b), chemical formula of citric acid $\left(\mathrm{C}_{6} \mathrm{H}_{8} \mathrm{O}_{7}\right)$.

To study the effect of the electrolyte concentration on the aluminium oxide surface morphology, field-emission scanning electron microscopy (FE-SEM) and atomic force microscopy (AFM) have been utilized. Figure 2 (a) and (b) show FE-SEM and AFM images of oxide dielectric films anodized in 1 and $1000 \mathrm{mM} \mathrm{CA}$ after annealing at $120{ }^{\circ} \mathrm{C}$, respectively. The films appear to be very smooth and no pronounced features can be seen. AFM topography reveals that the RMS area roughness $\left(S_{\mathrm{q}}\right)$ of both aluminium oxide film surfaces are about $5 \AA$ which confirms that the surface of the anodized $\mathrm{Al}$ is relatively smooth (cf. insets of Figure 2 (a) and (b), respectively). As a result, we conclude that the influence of CA concentration on the surface roughness of anodized aluminium is negligible. Intriguingly, AFM imgages displayed in the insets of Figure 2 (a) and (b) suggest that the obtained oxide surface has a nanograin like structure. Since it is known that anodically oxidized aluminium is amorphous (26), to undesrtand the origin of this phenomenon, AFM topography measurements of Al films before and after anodization were also performed. As 
evidenced by the AFM topography images shown in the Supplementary Material Figure S2(a), it appears that the observed nanograin like structure is due to the initial morphology of the Al films. Indeed, as supported by the XRD study shown in the Supplementary Material Figure S3, the imaged nanodomains are amorphous. Whereas the $S_{\mathrm{q}}$ of the pristine $\mathrm{Al}$ films is about $10 \AA$, the $S_{\mathrm{q}}$ of the aluminium oxide films is only $5 \AA$. This result shows that the anodization of Al films results in much smoother surfaces and suggests that the aluminium oxide follows the original structure of the "seed" Al. Interestingly, as shown in the the Supplementary Material Figure S2(b), the RMS area roughness of anodically oxidized aluminium oxide can be reduced further from 5 to $4 \AA$ by the application of OTS SAM.

To study the elemental composition of the prepared oxide films, energy-dispersive X-ray spectroscopy (EDS) has been performed. Figure 2 (c) and (d) show EDS spectra of aluminium oxide prepared in 1 and $1000 \mathrm{mM}$ electrolyte concentrations, respectively. The EDS data has been compiled in Table 1. The analysis of the recorded spectra confirms that there is virtually no difference in the composition of both types of films. No traces of carbon in the anodized films of aluminium presented here is in strong contrast to the citric acid anodized tantalum films reported previously where incorporation of citric acid anion was observed (20). It is also crucial to note here that the peaks appeared on EDS spectra for the elements sodium $(\mathrm{Na})$, calcium $(\mathrm{Ca})$, and silicon ( $\mathrm{Si}$ ) originates from the used glass substrates. 

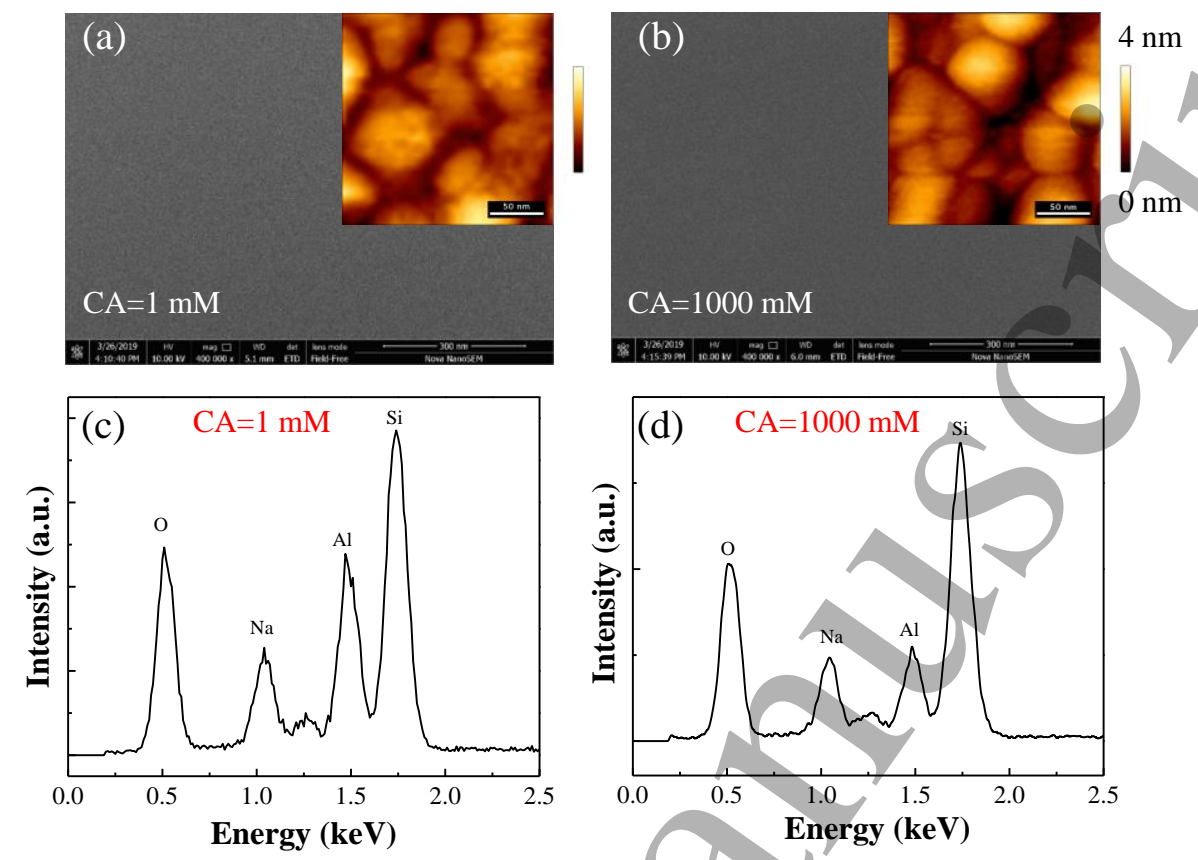

Figure 2. (a) and (b) SEM topographic images of anodized aluminium films prepared using $1 \mathrm{mM}$ and $1000 \mathrm{mM}$ citric acid concentrations, respectively. Scale bar for both SEM images is $300 \mathrm{~nm}$. Inset of (a) and (b) shows the topographic images using AFM for both films mentioned in (a) and (b), respectively. Scale bar for both AFM images is $50 \mathrm{~nm}$. (c) and (d) EDS data recorded for both above-mentioned films used to identify their elemental composition.

Table 1: EDS elemental analysis of anodized Al films for 1 and $1000 \mathrm{mM}$ concentrations of citric acid.

\begin{tabular}{|c|c|c|c|c|c|c|c|}
\hline EDS & $\begin{array}{c}\text { Concentration } \\
(\mathrm{mM})\end{array}$ & $\mathrm{Na}$ & $\mathrm{Ca}$ & $\mathrm{Si}$ & $\mathrm{Al}$ & $\mathrm{O}$ & Total \\
\hline \multirow{2}{*}{ Weight\% } & 1 & 7.6 & 6.5 & 34.3 & 13.5 & 38.0 & 100 \\
\cline { 2 - 7 } & 1000 & 7.5 & 5.0 & 34.7 & 15.4 & 37.4 & 100 \\
\hline \multirow{2}{*}{ Atom\% } & 1 & 7.2 & 3.5 & 26.6 & 10.9 & 51.7 & 100 \\
\cline { 2 - 8 } & 1000 & 7.1 & 2.7 & 26.9 & 12.4 & 50.9 & 100 \\
\hline
\end{tabular}

To determine the influence of the CA concentration on the chemical stoichiometry of the anodized Al films XPS technique was employed. The survey spectrum scan of two aluminium oxide films 
anodized with CA concentration of 1 and $1000 \mathrm{mM}$ are shown in the Figure 3 (a) and (d), respectively. The charging effect was adjusted for both films by considering the BE position of $\mathrm{C} 1 \mathrm{~s}$ peak at $284.8 \mathrm{eV}$ of carbon-carbon bond (C-C). It has been reported that the $\mathrm{C} 1 \mathrm{~s}$ peak appears due to carbon contamination if film is exposed to a moist environment (27). As can be seen on the survey scan for both the films, the binding energy (BE) position of Al2p and O1s appeared at 74.8 and $535.8 \mathrm{eV}$, respectively, which indicates that the major components of these films are aluminium and oxygen in some composite form due to the shifting from the pristine Al2p peak. Actually, the BE position of Al2p peak for pure Al metal is located at $72.5 \pm 0.3 \mathrm{eV}$. To confirm the exact composition of the films further, high-resolution spectrum of O1s have been recorded as shown in the Figure 3 (b) and (e), respectively. Here, the photoelectron peaks at 535.7 and 527.2 $\mathrm{eV}$ of BE positions are actually generated from the used glass substrates as shown in the inset of Figure 3(e). Therefore, the peak at $\mathrm{BE}$ of $531.5 \mathrm{eV}$ is the characteristic spectral line from the oxygen of anodized Al films as supported by the NIST XPS database (28). Further, the highresolution spectrum of A12p is also recorded for BE peak at $\sim 74.9 \mathrm{eV}$ without any energy splitting for both films as shown in the Figure 3 (c) and (f), respectively. Deconvolution results in two peaks inside the each $\mathrm{Al} 2 \mathrm{p}$ envelop with the $\mathrm{BE}$ position at $\sim 74.9 \mathrm{eV}$ and $\sim 75.7 \mathrm{eV}$ as shown in the Figure 3 (c) and (f) for the films grown using CA concentration of $1 \mathrm{mM}$ and $1000 \mathrm{mM}$, respectively. These BE positions of A12p are indicating the growth of aluminium oxide films using $\mathrm{Al}$ anodization in $\mathrm{CA}$ as a very strong evidence of $\mathrm{Al}_{2} \mathrm{O}_{3}$ composition from NIST XPS spectral line database $(29,30)$. Interestingly, the Al2p spectral line peak at BE $~ 75.7 \mathrm{eV}$ can also indicate the presence of $\mathrm{Al}(\mathrm{OH})_{3}$. However, the recorded $\mathrm{Al} 2 \mathrm{p}$ peak here shows a FWHM value of $2.01 \mathrm{eV}$ which strongly recommends that the composition of films is $\mathrm{Al}_{2} \mathrm{O}_{3}$ (31). As a result, the XPS 

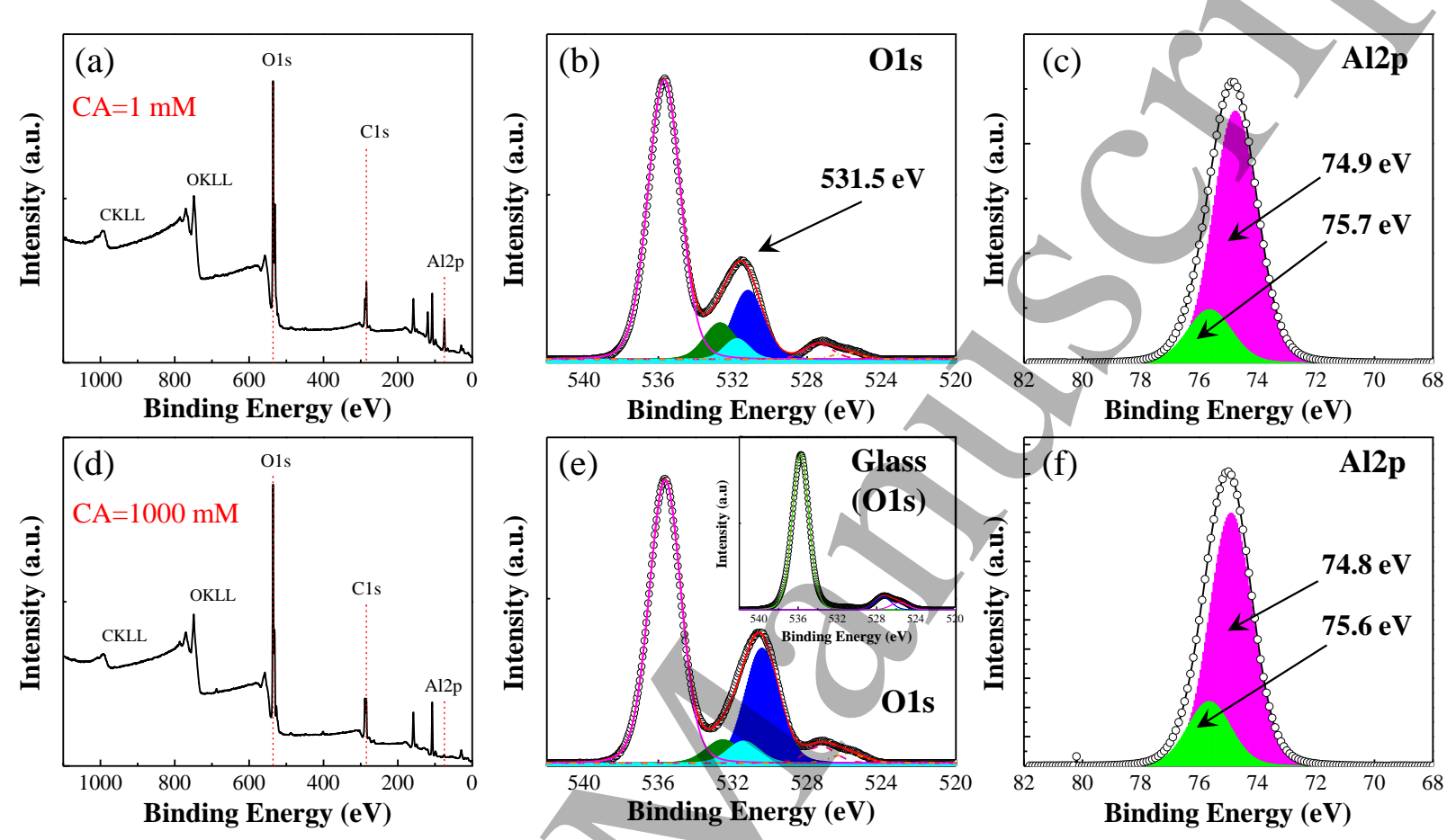

Figure 3. (a) and (d) XPS survey scans of the anodized aluminium films grown on glass substrates using $1 \mathrm{mM}$ and 1000mM concentrations, respectively. (b) and (e) high resolution spectra of O1s peak with deconvolution fittings for the same films, respectively. Inset of (e) is the high resolution spectrum of O1s peak recorded from blank glass substrate. (c) and (f) are high resolution spectra of A12p peak with deconvolution fittings for both samples as described above.

To investigate the effect of $\mathrm{CA}$ concentration on the dielectric properties of ultra-thin $\mathrm{Al}_{2} \mathrm{O}_{3}$ films anodized at $V_{A}=5.0 \mathrm{~V}$, electrochemical impedance spectroscopy (EIS) techniques were employed. For all EIS characterizations, the devices having meal-insulator-metal (MIM) capacitor structure as shown in Figure 4(a) as schematics were used. Since penetration of ionic species into the prepared $\mathrm{Al}_{2} \mathrm{O}_{3}$ films could have large influence on their dielectric behaviour, EIS studies of the $\mathrm{Al}_{2} \mathrm{O}_{3}$ films grown using six different CA concentrations starting from 0.1 to $1000 \mathrm{mM}$ were 
performed in the $100 \mathrm{mHz}$ to $100 \mathrm{kHz}$ frequency range as depicted in Figure 4 (b) and (c). The analysis of the EIS results enables precise quantification of the probability of carbon contamination in the form of citrate anion $\left(\mathrm{C}_{6} \mathrm{H}_{5} \mathrm{O}_{7}^{3-}\right)$ penetration. Frequency dependence of impedance $(\mathrm{Z})$ and phase $(\varphi)$ of all $\mathrm{Al}_{2} \mathrm{O}_{3}$ films are shown in Figure 4 (b) which are commonly known as Bode plots. The low frequency region for both $\mathrm{Z}$ and $\varphi$ shows a plateau and a dip, respectively, due to the slow formation of space charge resulting from electrical double layer (EDL) at both metal-insulator interfaces. After the formation of the stable EDL at the interfaces, devices show almost ideal capacitive nature with phase lag of nearly $\varphi \approx-90^{\circ}$ between $10 \mathrm{~Hz}$ to $100 \mathrm{kHz}$. Inset of Figure 2(b) shows the almost similar phase lag $\left(\varphi \approx-90^{\circ}\right)$ at $1.0 \mathrm{kHz}$ for all six samples prepared using different CA concentrations. This strongly indicates the invariance of dielectric properties among all $\mathrm{Al}_{2} \mathrm{O}_{3}$ films. However, OTS coating on top of the $\mathrm{Al}_{2} \mathrm{O}_{3}$ films improves overall frequency response between $100 \mathrm{mHz}$ to $100 \mathrm{kHz}$ with slight decrease in phase lag as shown in Figure 2(b). Specific capacitances $\left(C_{i}=\varepsilon_{0} \varepsilon^{\prime} / d\right)$ for all samples are calculated from the measured impedance data and shown in Figure 4(c) in the same frequency range (i.e. from $100 \mathrm{mHz}$ to $100 \mathrm{kHz}$ ). Here, the OTS coating on $\mathrm{Al}_{2} \mathrm{O}_{3}$ films again improves the frequency response as steep region at the lower frequency side of the spectrum is significantly minimized with a small sacrifice of the $C_{\mathrm{i}}$ value. It is also important to note that the specific capacitances for all devices show the same value of approximately $600 \mathrm{nF} / \mathrm{cm}^{2}$ at $1.0 \mathrm{kHz}$ as depicted in the inset of Figure 4(c). $C_{\mathrm{i}}$ is reduced to slightly below $400 \mathrm{nF} / \mathrm{cm}^{2}$ by incorporating OTS SAM. Importantly, the ideal capacitor characteristics for all investigated ultra-thin, anodized Al films with negligible variation strongly suggests the absence of any ionic species in the $\mathrm{Al}_{2} \mathrm{O}_{3}$ films. 


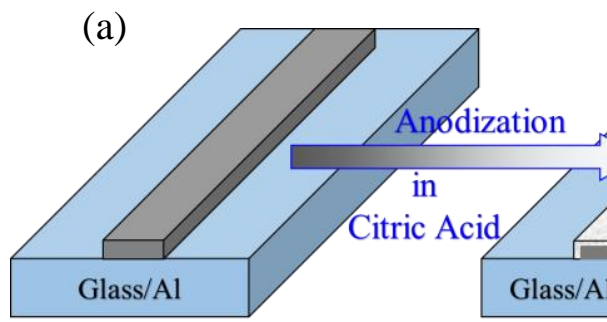

(b)
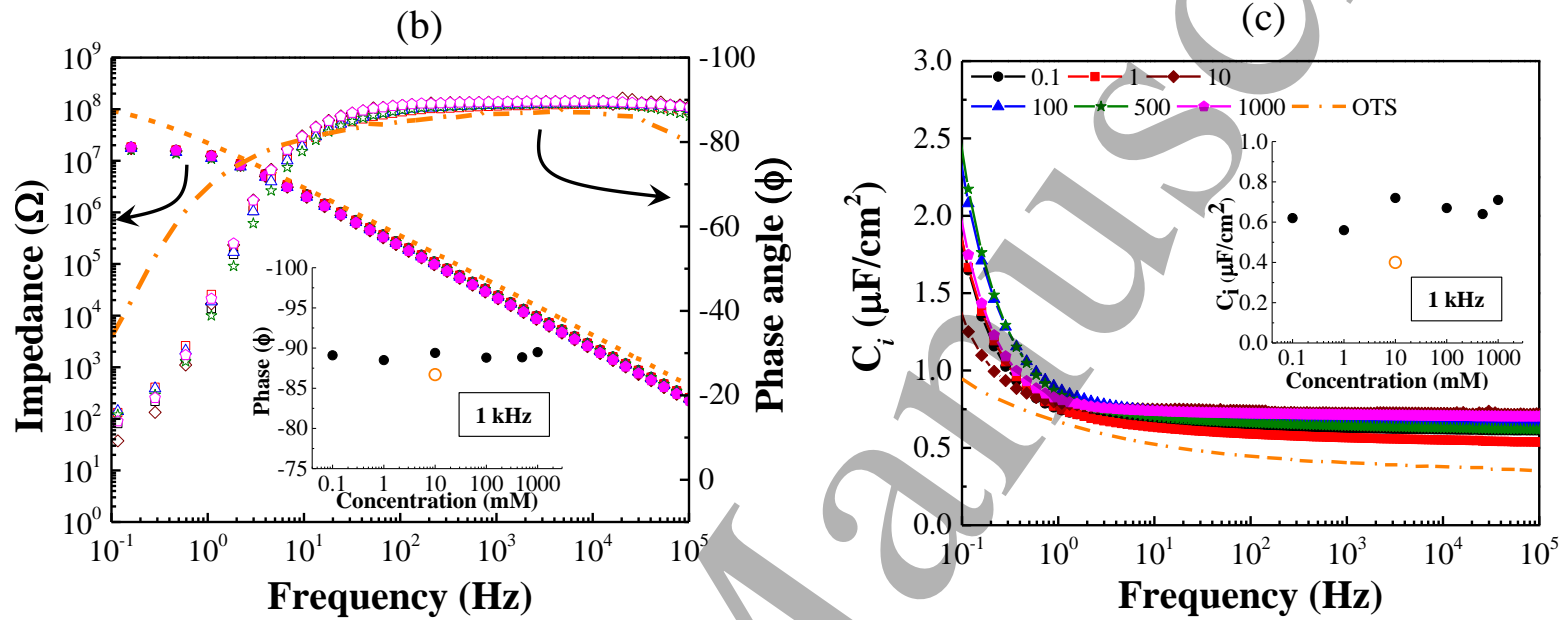

Figure 4. (a) Crossbar structure device schematic of the fabricated MIM capacitors. (b) Bode plot (Impedance $Z(\mathrm{Ohm})$ and Phase angle $\varphi$ (degrees) vs. frequency) of the measured impedance data for all devices. Inset shows the variation of phase lag at $1 \mathrm{kHz}$ for all $\mathrm{CA}$ concentrations including OTS coated sample (for $10 \mathrm{mM}$ ). (c) Variation of the specific capacitances as a function of frequency $\left(C_{\mathrm{i}}-f\right)$ for all fabricated MIM capacitors. Inset shows the variation of specific capacitance at $1 \mathrm{kHz}$ for all CA concentrations including OTS coated sample ( for $10 \mathrm{mM}$ ).

Frequency dependence of the dielectric constant $\left(\varepsilon^{\prime}\right)$ and dielectric loss $\tan (\delta)$ were calculated for all devices from the EIS measurement data and plotted as the function of frequency as shown in Figure 5(a). The results show that the dielectric constant is high in the low frequency region $(f<1$ $\mathrm{Hz})$ for all devices. However, $\varepsilon^{\prime}$ starts to decrease rapidly when the frequency starts to increase above $1 \mathrm{~Hz}$ because the electric dipoles in $\mathrm{Al}_{2} \mathrm{O}_{3}$ are unable to follow the variation of the applied 
AC electric field at higher frequencies. Here, it can be observed that the magnitude of the dielectric constant remains almost independent of the molar concentrations of CA from $1 \mathrm{~Hz}$ to $100 \mathrm{kHz}$ as shown in the inset of Figure 5 (a). All devices show the dielectric constant value around 6.0 for the oxide layer thickness of approximately $6.5 \mathrm{~nm}$ (excluding the native oxide) as depicted in the inset of Figure 5(a). It is reasonable to assume that the dielectric constant is significantly reduced from the oxide bulk values when the thickness of the dielectric layer is $\leq 10 \mathrm{~nm}$. This could be due to non-stoichiomtery of thin oxide films but also because of the dominant nature of the interfacial layers between the oxide and electrodes that reduce the bulk phase property as observed in the previous report (32). The OTS passivation of the $\mathrm{Al}_{2} \mathrm{O}_{3}$ surface reduces the effective dielectric constant to 3.0. However, the capacitor behaviour in terms of the frequency response range somewhat improves as can be seen in Figure 5(a). The quantity $\tan (\delta)$ is referred to as dielectric loss. Normally, the dielectric loss occurs due to the absorption of electrical energy which is used to rotate the dipoles in dielectric films (33). In nanomaterials, the lack of film homogeneity can induce an absorption current due to the formation of space charge which also contributes to the dielectric loss (34). In addition, the presence of the highly reactive dangling bonds on top of oxide thin film surfaces can give rise to absorbtion of gases like oxygen or nitrogen which may also result in an increase of the dielectric loss. The variation of $\tan (\delta)$ with frequency is shown in Figure 5(a) without and with OTS coating for $10 \mathrm{mM} \mathrm{CA}$ oxide films. As can be seen in the inset of Figure 5(b), the dielectric loss was found to be below 0.1 at $1 \mathrm{kHz}$ for all investigated samples. The variation of the $\mathrm{AC}$ conductivity $\left(\sigma_{\mathrm{AC}}\right)$ with the frequency for all fabricated capacitors is shown in the Figure 5(b). $\sigma_{\mathrm{AC}}$ is found to be almost invariant at lower frequencies for all cases except the OTS one. As expected, the AC conductivity increases due to dispersion and charge carrier hopping in the films when the frequency exceeds $100 \mathrm{~Hz}$. It can be noticed in Figure 5(b) 
that the behaviour of $\sigma_{\mathrm{AC}}$ is similar for all devices independently of the used CA concentration. Surprisingly, as shown in the inset of Figure 5(b), $\mathrm{Al}_{2} \mathrm{O}_{3} / \mathrm{OTS}$ devices show somewhat higher dielectric loss compared with $\mathrm{Al}_{2} \mathrm{O}_{3}$ only devices. This could be due to the contribution of SAM to the overall AC conductivity of the $\mathrm{Al}_{2} \mathrm{O}_{3}$ /OTS stack. Therefore, we conclude that the penetration of ionic species into the $\mathrm{Al}_{2} \mathrm{O}_{3}$ films is very unlikely.

The dielectric quality of the anodized Al films is further studied by measuring their breakdown voltage $\left(V_{\mathrm{B}}\right)$. As shown in the Supplementary Material Figure $\mathrm{S} 4$ (a) and (b), the devices show $V_{\mathrm{B}}$ about $5 \mathrm{~V}$ which is almost the same as the chosen anodization voltage. Therefore, we speculate that the anodization voltage is the most important parameter which decides the value of the breakdown voltage. Also, the obtained results clearly show that the annealing the $\mathrm{Al}_{2} \mathrm{O}_{3}$ films at $120^{\circ} \mathrm{C}$ has no obvious influence on $V_{\mathrm{B}}$.

(a)

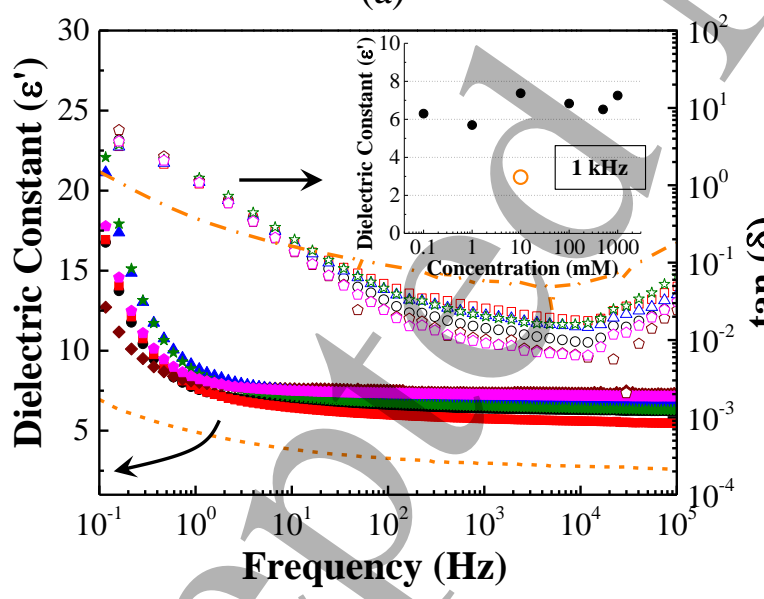

(b)

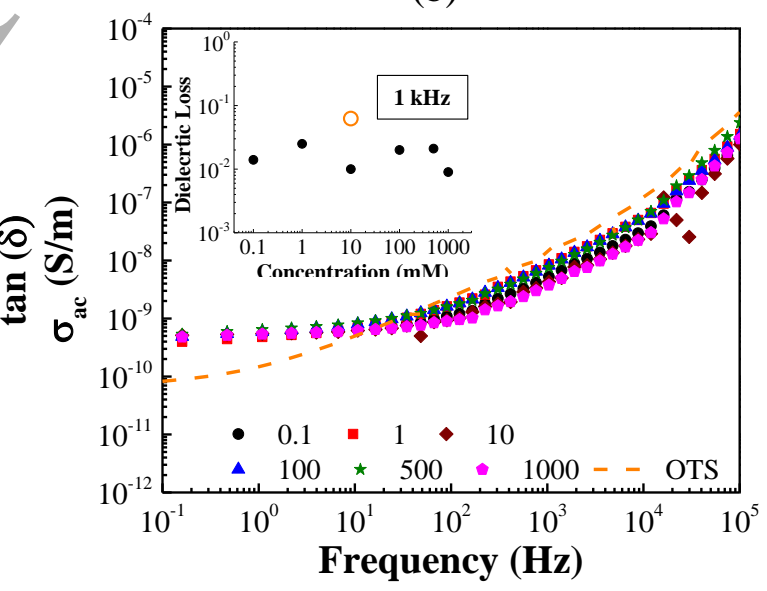

Figure 5. (a) Variation of the dielectric constant $\left(\varepsilon^{\prime}\right)$ and dielectric loss $(\tan (\delta))$ vs. frequency $(f)$ of the studied MIM capacitors extracted from the measured impedance data. Inset shows the variation of dielectric constant at $1 \mathrm{kHz}$ for all CA concentrations including OTS coated sample $(10 \mathrm{mM})$. (b) variation of AC conductivity $\left(\sigma_{A C}\right)$ with frequency $(f)$ for all six devices prepared 
with citric acid strength from 0.1 to $1000 \mathrm{mM}$. Inset shows the variation of dielectric loss at $1 \mathrm{kHz}$ for all CA concentrations including OTS coated sample (10 mM).

Figure 6 (a) and (b) show the experimental Nyquist plots with fitted data of the $\mathrm{Al}_{2} \mathrm{O}_{3}$ films grown using CA concentrations for 10 and $1000 \mathrm{mM}$, respectively, for MIM capacitors with overlapping area $1.0 \mathrm{~mm}^{2}$ in which negative value of imaginary impedance $\left(-Z^{\prime \prime}\right)$ is plotted with real impedance (Z') (35). The semicircle diameter reflects the sum of the contact resistance $\left(R_{\mathrm{S}}\right)$ and the bulk resistance $\left(R_{\mathrm{CT}}\right)$ of the device which appear slightly different for two films prepared with $\mathrm{CA}$ concentration 10 and $1000 \mathrm{mM}$ due to a minimal difference of the resistance value. To understand more precisely, the impedance data in Nyquist plot is fitted for both cases using an RC equivalent circuit containing different components as shown in Figure 6(c). This equivalent circuit contains a contact resistance $\left(R_{\mathrm{S}}\right)$ in series with a parallel combination of a constant phase element $(Q)$ and a Warburg impedance $(W)$ in series with bulk resistance $\left(R_{\mathrm{CT}}\right)$. The impedance of a constant phase element $(\mathrm{Q})$ is expressed as $Z_{Q}=1 /\left[(j \omega)^{\alpha} \cdot Y\right]$ and this equation describes a capacitor with the constant $\mathrm{Y}=\mathrm{C}$ (the capacitance) when the exponent $\alpha=1$. Usually, $\alpha$ is less than 1 for non-ideal capacitors. Interestingly, both studied capacitors show the value of $\alpha=1.0$ which strongly suggest that the ultra-thin films prepared by anodization in CA with varying concentrations are free of defects and ionic carbon contamination (36). On the other hand, capacitance-voltage $(C-V)$ measurements at $1 \mathrm{kHz}$ for a device fabricated using $10 \mathrm{mM} \mathrm{CA}$ concentration show that the capacitance is independent of applied voltage between -1.0 to $+1.0 \mathrm{~V}$ as depicted in Figure 6 (d). Surprisingly, the measured value of $\mathrm{C}=7.25 \mathrm{nF}$ is also perfectly matching the evolved capacitance value from the fitting result of Nyquist data for both CA concentrations. Therefore, it can be concluded that all anodized aluminium films appear to be free of ionic species even by changing the strength of electrolyte by 4 orders of magnitude. 

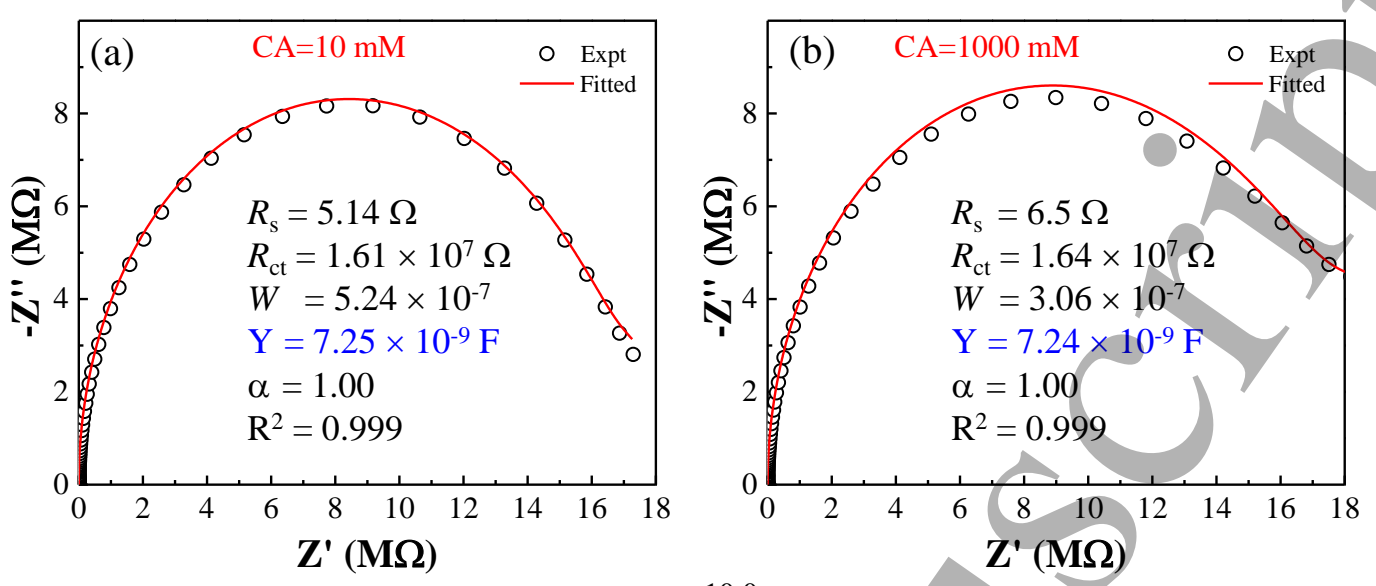

(c)

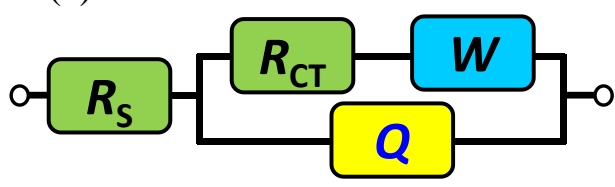

$R_{\mathrm{S}} \quad$ : Contact Resistance

$R_{\mathrm{ct}} \quad$ : Charge-transfer resistance

$W \quad$ : Warburg Impedance

Q : Constant Phase Element

$\mathrm{R}^{2} \quad$ : Fitting parameter

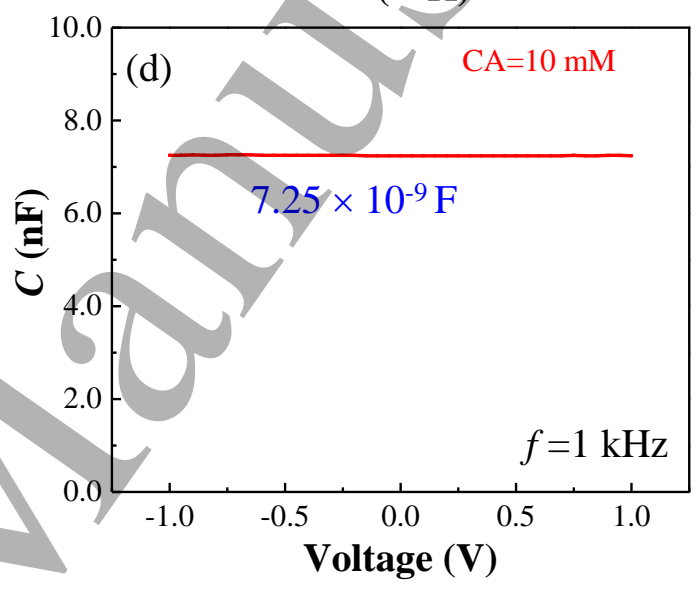

Figure 6. Nyquist plots with the fitting curve to model the anodized films grown using $10 \mathrm{mM}$ (a) and $1000 \mathrm{mM}$ (b) citric acid solutions. The insets show the list of the components with their correcsponding values used for the fitting analysis. (c) An equivalent RC network circuit used to perform the fitting analysis for the experimental data in the Nyquist plots. (d) Capacitance vs. voltage $(C-V)$ characteristic for the device prepared using $10 \mathrm{mM} \mathrm{CA}$ maintaining constant frequency at $1 \mathrm{kHz}$. 
(a)

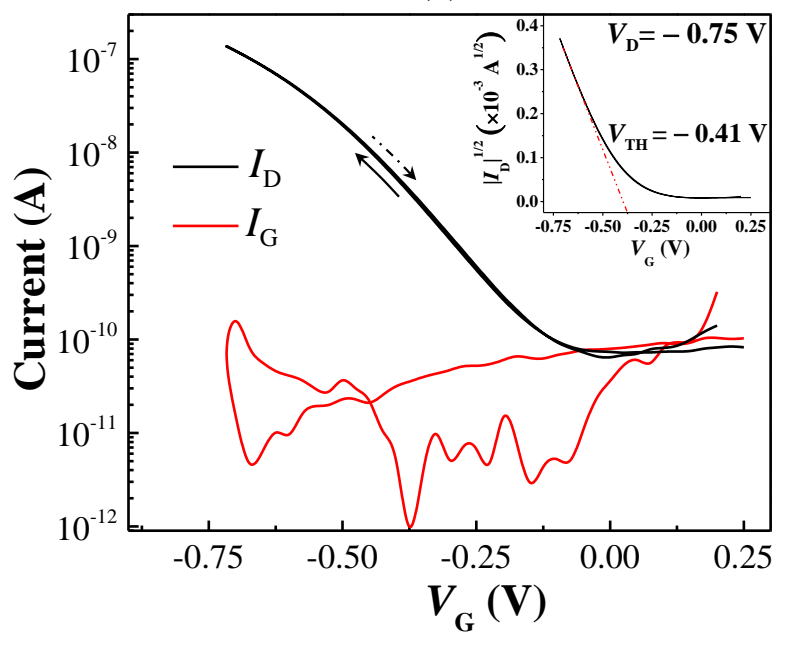

(b)

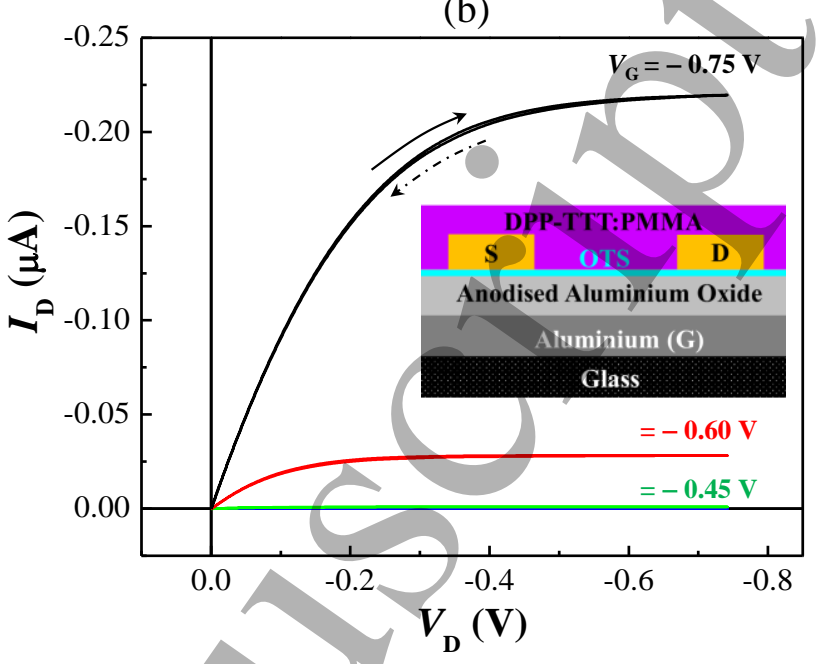

Figure 7. Representative(a) transfer (black line) with leakage current (red line) and (b) output characteristics of the fabricated bottom-gate bottom-contact DPP-TTT OTFTs. The inset in (a) shows $I_{\mathrm{D}}^{1 / 2}$ vs. $V_{\mathrm{G}}$ plot used to find threshold voltage $\left(V_{\mathrm{TH}}\right)$. The inset in (b) shows the crosssectional structure of the fabricated transistors using OTS-modified, anodized aluminium as the gate dielectric.

To test if the optimized $\mathrm{Al}_{2} \mathrm{O}_{3}$ films result in well working transistors, bottom-gate bottom-contact DPP-TTT:PMMA OTFTs with OTS-modified aluminium oxide $\left(\mathrm{Al}_{2} \mathrm{O}_{3}\right)$ anodized at $V_{\mathrm{A}}=2.3 \mathrm{~V}$ $(\mathrm{d} \sim 3 \mathrm{~nm}$ ) have been fabricated (inset of Figure 7 (b)). Typical output and transfer characteristics of the fabricated OTFTs are shown in Figure 7 (a) and 7 (b), respectively. Threshold voltage $\left(V_{\mathrm{TH}}\right)$ is an important parameter which has influence on the operation mode as well as carrier mobility. Here, $V_{\mathrm{TH}}$ is estimated about $-0.41 \mathrm{~V}$ from the $\operatorname{sqrt}\left(I_{\mathrm{D}}\right)$ vs. $V_{\mathrm{G}}$ plot (inset of Figure 7 (a)). This negative value of $V_{\mathrm{TH}}$ indicates that the channel is p-type and it operates in the enhancement mode. The optimized devices operate below $1 \mathrm{~V}$ with virtually no hysteresis, the saturation field-effect mobility $\left(\mu_{\text {sat }}\right)$ is $0.1 \mathrm{~cm}^{2} \mathrm{~V}^{-1} \mathrm{~s}^{-1}$, the threshold voltage $-0.41 \mathrm{~V}$, subthreshold swing $155 \mathrm{mV} / \mathrm{dec}$, and the current on/off ratio is in excess of $10^{3}$. In addition, the leakage current measured at -700 
$\mathrm{mV}$ is well below $0.1 \mathrm{nA}$ and remains below that value for all applied biases. As can bee seen, the achived performance of the devices is comparable with the recently reported state-of-the-art $1 \mathrm{~V}$ OTFTs (37).

\section{CONCLUSIONS}

In conclusion, ultra-thin $(\mathrm{d}<10 \mathrm{~nm})$, barrier type aluminium oxide films were grown anodically in citric acid electrolyte solutions of various concentrations. The SEM and AFM data reveal that the surface of the anodized films is very smooth and pinhole free. The EDS scans and XPS spectra show that the films are free from carbon contamination which suggests that the citrate anions are not present in the anodized films. The XPS results further confirm that the obtained oxide films consist of a stochiometric $\mathrm{Al}_{2} \mathrm{O}_{3}$ even when changing the electrolyte strength from 1 to $1000 \mathrm{mM}$. The analysis of impedance spectroscopy results strongly confirms that the CA concentration does not play any significant role in the control of the dielectric properties of such films. The effect of OTS SAM on the dielectric properties of the anodized Al films has also been studied. It is found that there is a noticeable improvement in terms of frequency bandwidth but all values related to the dielectric properties decrease as expected because of the increase in overall thickness. Finally, high capacitance $\mathrm{Al}_{2} \mathrm{O}_{3}$ films were used to fabricate organic TFTs. Low operational voltage devices were achieved by using extremely thin $(3 \mathrm{~nm}) \mathrm{Al}_{2} \mathrm{O}_{3}$ films that were modified by the application of an OTS SAM. The optimized DPP-TTT:PMMA transistors display threshold voltages around $-0.41 \mathrm{~V}$, low subthreshold slopes $155 \mathrm{mV} / \mathrm{dec}$, they operate with negligible hysteresis and possess average saturated field-effect mobility $\left(\mu_{\text {sat }}\right)$ in excess of $0.1 \mathrm{~cm}^{2} \mathrm{~V}^{-1} \mathrm{~s}^{-1}$ at $750 \mathrm{mV}$. This approach has a high potential to enable the fabrication of ultra-low voltage organic TFTs in a highly reproducible manner. 


\section{ACKNOWLEDGEMENTS}

This work is supported by the UGC-UKIERI Joint Research Programme (UKIERI-III) 2017/18015, 184-15/2018(IC) and by the SERB, India (EEQ/2016/000045). Partial support also received from the IISER-TVM start up grant and SERB, India (ECR/2017/000630). S.K.S. acknowledges JRF fellowship offered by IISER-TVM for doing Ph.D..

\section{REFERENCES}

1. Gao D, Tan ZW, Fan Z, Guo M, Hou ZP, Chen DY, et al. All-Inorganic Flexible $\mathrm{Ba}_{0.67} \mathrm{Sr}_{0.33} \mathrm{TiO}_{3}$ Thin Films with Excellent Dielectric Properties over a Wide Range of Frequencies. ACS Appl Mater Inter. 2019;11(30):27088-97.

2. Zhuang JQ, Sun QJ, Zhou Y, Han ST, Zhou L, Yan Y, et al. Solution-Processed Rare-Earth Oxide Thin Films for Alternative Gate Dielectric Application. ACS Appl Mater Inter. 2016;8(45):31128-35.

3. Zschieschang U, Bader VP, Klauk H. Below-one-volt organic thin-film transistors with large on/off current ratios. Org Electron. 2017;49:179-86.

4. Kuribara K, Nobeshima T, Kodzasa T, Uemura S, Yoshida M. Atmospheric-pressure plasma oxidation of aluminum for large-area electronics. J Appl Phys. 2019;125(21).

5. Wang QH, Wu SH, Ge F, Zhang GB, Lu HB, Qiu LZ. Solution-Processed Microporous Semiconductor Films for High-Performance Chemical Sensors. Adv Mater Interfaces. 2016;3(22).

6. Wang NX, Yang AN, Fu Y, Li YZ, Yan F. Functionalized Organic Thin Film Transistors for Biosensing. Accounts Chem Res. 2019;52(2):277-87.

7. Sagar S, Dey A, Das BC. Unconventional Redox-Active Gate Dielectrics To Fabricate High Performance Organic Thin-Film Transistors. ACS Applied Electronic Materials. 2019;1(11):2314-24.

8. Dollinger F, Lim KG, Li Y, Guo E, Formanek P, Hubner R, et al. Vertical Organic Thin-Film Transistors with an Anodized Permeable Base for Very Low Leakage Current. Adv Mater. 2019;31(19):e1900917.

9. Cai WS, Park S, Zhang JW, Wilson J, Li YP, Xin Q, et al. One-Volt IGZO Thin-Film Transistors With Ultra-Thin, Solution-Processed $\mathrm{Al}_{\mathrm{x}} \mathrm{O}_{\mathrm{y}}$ Gate Dielectric. Ieee Electr Device L. 2018;39(3):375-8.

10. Siket CM, Tillner N, Mardare AI, Reuveny A, Grill CD, Hartmann F, et al. Direct writing of anodic oxides for plastic electronics. npj Flexible Electronics. 2018;2(1):23.

11. Zhang F, Ju PF, Pan MQ, Zhang DW, Huang Y, Li GL, et al. Self-healing mechanisms in smart protective coatings: A review. Corros Sci. 2018;144:74-88.

12. Sun S, Lan LF, Xiao P, Chen ZH, Lin ZG, Li YZ, et al. High mobility flexible polymer thin-film transistors with an octadecyl-phosphonic acid treated electrochemically oxidized alumina gate insulator. J Mater Chem C. 2015;3(27):7062-6.

13. Birey H. Dielectric Properties of Aluminum-Oxide Films. J Appl Phys. 1978;49(5):2898-904.

14. Koslowski N, Sanctis S, Hoffmann RC, Bruns M, Schneider JJ. Synthesis, dielectric properties and application in a thin film transistor device of amorphous aluminum oxide $\mathrm{Al}_{\mathrm{x}} \mathrm{O}_{\mathrm{y}}$ using a molecular based precursor route. J Mater Chem C. 2019;7(4):1048-56.

15. Hourdakis E, Nassiopoulou AG. Reaching state-of-the art requirements for MIM capacitors with a single-layer anodic $\mathrm{Al}_{2} \mathrm{O}_{3}$ dielectric and imprinted electrodes. Appl Phys Lett. 2017;111(3).

16. Chiu RL, Chang PH, Tung $\mathrm{CH}$. $\mathrm{Al}_{2} \mathrm{O}_{3}$ Films Formed by Anodic-Oxidation of Al-1 Weight Percent Si-0.5 Weight Percent Cu Films. J Electrochem Soc. 1995;142(2):525-31. 
17. Dang XD, Plieth W, Richter S, Ptotner M, Fischer WJ. Aluminum oxide film as gate dielectric for organic FETs: Anodization and characterization. Phys Status Solidi A. 2008;205(3):626-32.

18. Mohammadian N, Faraji S, Sagar S, Das BC, Turner ML, Majewski LA. One-Volt, SolutionProcessed Organic Transistors with Self-Assembled Monolayer- $\mathrm{Ta}_{2} \mathrm{O}_{5}$ Gate Dielectrics. Materials. 2019;12(16).

19. Lin YP, Hwu JG. Using anodization to oxidize ultrathin aluminum film for high-k gate dielectric application. J Electrochem Soc. 2003;150(7):G389-G94.

20. Kim YH, Uosaki K. Preparation of Tantalum Anodic Oxide Film in Citric Acid Solution - Evidence and Effects of Citrate Anion Incorporation. J Electrochem Sci Te. 2013;4(4):163-70.

21. Sharp DJ, Panitz JKG, Merrill RM, Haaland DM. The Incorporation of Electrolyte by-Products into Barrier Anodic Al2o3 Coatings. Thin Solid Films. 1984;111(3):227-34.

22. Majewski LA, Grell M, Ogier SD, Veres J. A novel gate insulator for flexible electronics. Org Electron. 2003;4(1):27-32.

23. Majewski LA, Schroeder R, Grell M. Flexible high capacitance gate insulators for organic field effect transistors. J Phys D Appl Phys. 2004;37(1):21-4.

24. Diggle JW, Downie TC, Goulding CW. Anodic Oxide Films on Aluminum. Chem Rev. 1969;69(3):365-\&.

25. Stevan Stojadinovic' RV, Bec'ko Kasalica, Ivan Belc`a, and Ljubis`a Zekovic. Electrodeposition and Surface Finishing. New York: Springer-Verlag New York; 2014. 363 p.

26. Luo DX, Lan LF, Xu M, Xu H, Li M, Wang L, et al. Role of Rare Earth Ions in Anodic Gate Dielectrics for Indium-Zinc-Oxide Thin-Film Transistors. J Electrochem Soc. 2012;159(5):H502-H6.

27. Cordier F, Ollivier E. X-Ray Photoelectron-Spectroscopy Study of Aluminum Surfaces Prepared by Anodizing Processes. Surf Interface Anal. 1995;23(9):601-8.

28. Wagner CD, Passoja DE, Hillery HF, Kinisky TG, Six HA, Jansen WT, et al. Auger and Photoelectron Line Energy Relationships in Aluminum-Oxygen and Silicon-Oxygen Compounds. J Vac Sci Technol. 1982;21(4):933-44.

29. George VC, Dua AK, Agarwala RP. Deuterium Ion-Bombardment Behavior of Alumina Coatings. Thin Solid Films. 1988;165(1):L107-L10.

30. Filatova EO, Konashuk AS. Interpretation of the Changing the Band Gap of $\mathrm{Al}_{2} \mathrm{O}_{3}$ Depending on Its Crystalline Form: Connection with Different Local Symmetries. J Phys Chem C. 2015;119(35):2075561.

31. Lindsay JR, Rose HJ, Swartz WE, Watts PH, Rayburn KA. X-Ray Photoelectron Spectra of Aluminum Oxides - Structural Effects on Chemical-Shift. Appl Spectrosc. 1973;27(1):1-5.

32. Acharya J, Wilt J, Liu B, Wu J. Probing the Dielectric Properties of Ultrathin $\mathrm{Al} / \mathrm{Al}_{2} \mathrm{O}_{3} / \mathrm{Al}$ Trilayers Fabricated Using in Situ Sputtering and Atomic Layer Deposition. ACS Appl Mater Inter. 2018;10(3):311220.

33. Dickey JR, Davidson JL, Tzeng Y. Improved Dielectric-Properties for Anodic Aluminum-Oxide Films by Soft Hard 2-Step Electrolytic Anodization. J Electrochem Soc. 1989;136(6):1772-7.

34. Lee SJ, Kang KY, Han SK. Low-frequency dielectric relaxation of BaTiO3 thin-film capacitors. Appl Phys Lett. 1999;75(12):1784-6.

35. Mei BA, Munteshari O, Lau J, Dunn B, Pilon L. Physical Interpretations of Nyquist Plots for EDLC Electrodes and Devices. J Phys Chem C. 2018;122(1):194-206.

36. Hirschorn B, Orazem ME, Tribollet B, Vivier V, Frateur I, Musiani M. Constant-Phase-Element Behavior Caused by Resistivity Distributions in Films I. Theory. J Electrochem Soc. 2010;157(12):C452C7.

37. Urasinska-Wojcik B, Cocherel N, Wilson R, Burroughes J, Opoku J, Turner ML, et al. 1 Volt organic transistors with mixed self-assembled monolayer/ $\mathrm{Al}_{2} \mathrm{O}_{3}$ gate dielectrics. Org Electron. 2015;26:20-

4. 


\title{
Supplementary Material
}

\section{Ultra-thin Anodized Aluminium Dielectric Films: The Effect of Citric Acid Concentration and Low-Voltage Electronic Applications}

\author{
Srikrishna Sagar ${ }^{1}$ Navid Mohammadian², Seonghyun Park $^{2}$, \\ Leszek A. Majewski² ${ }^{2}$ and Bikas C. Das ${ }^{1, *}$ \\ ${ }^{1}$ Emerging Nanoelectronic Devices Research Laboratory (eNDR Lab), School of Physics, Indian
} Institute of Science Education and Research Thiruvananthapuram (IISER-TVM), Maruthamala PO, Vithura, Thiruvananthapuram 695551, Kerala, India.

${ }^{2}$ Department of Electrical and Electronic Engineering, The University of Manchester, Manchester M13 9PL, UK.

* Corresponding author

Email: bikas@iisertvm.ac.in

ORCID ID

Bikas C. Das: 0000-0002-4750-0542

Leszek A Majewski: 0000-0001-6544-1286

Seonghyun Park: 0000-0003-3738-5883 
(a)

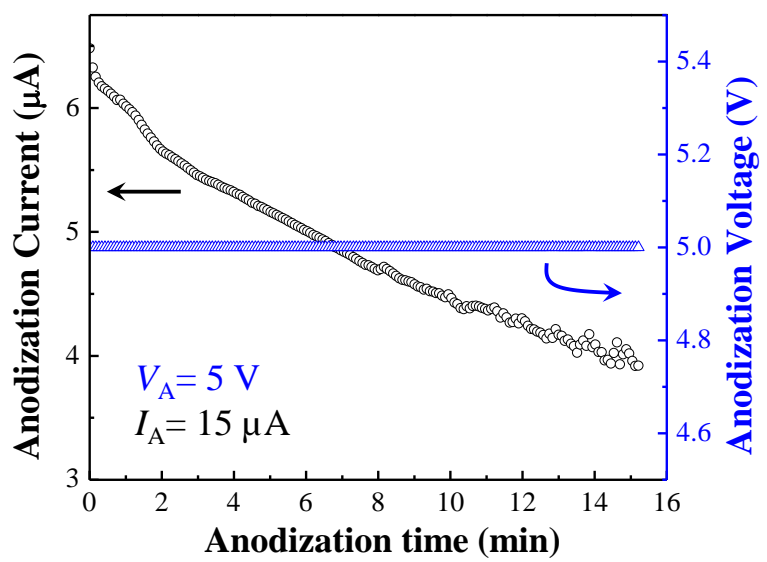

(b)

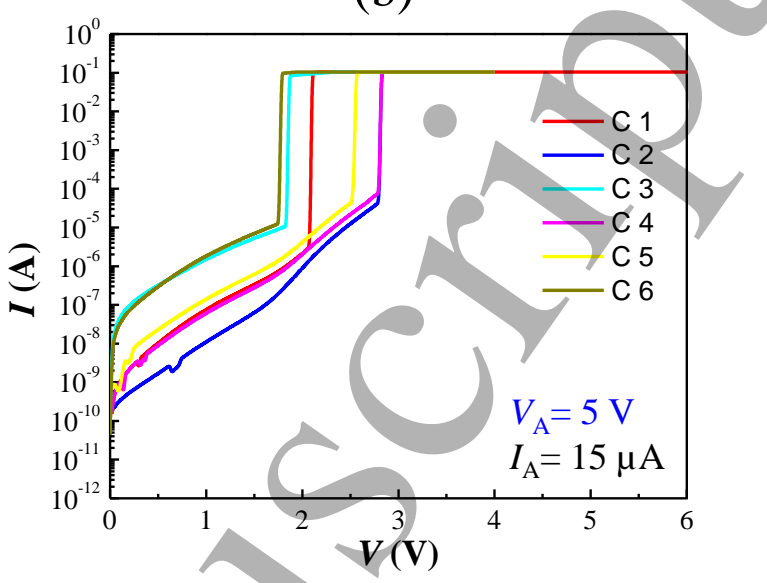

Figure S1. (a) Profiles of anodization current $\left(I_{\mathrm{A}}\right)$ (black circles) and anodization voltage $\left(V_{\mathrm{A}}\right)$ (blue triangles) as the function of anodization time $(t)$ using high purity DI water as the electrolyte. (b) Breakdown voltage $\left(V_{\mathrm{B}}\right)$ measurements of six randomly chosen $\mathrm{Al} / \mathrm{Al}_{2} \mathrm{O}_{3} / \mathrm{Al}$ MIM capacitors ( $\mathrm{C} 1$ to $\mathrm{C} 6$ ) fabricated on the same glass substrate using high purity DI water as the electrolyte. It can be noticed that the value of $V_{B}$ substantially varies from device to device.

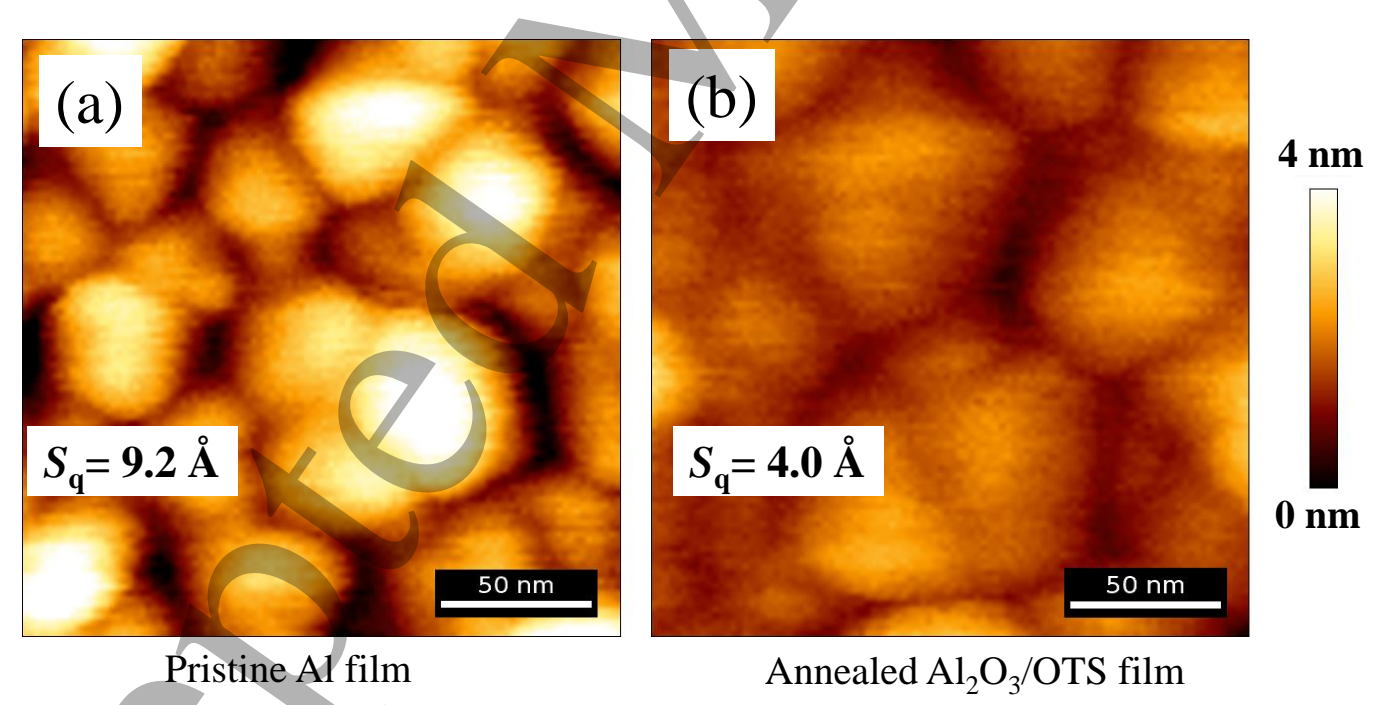

Figure S2. (a) AFM topography image of pristine Al film (100 nm thick) is recorded immediately after deposition on ultra-flat glass which shows RMS area roughness $\left(S_{\mathrm{q}}\right)$ about $9.2 \AA$. (b) AFM topography image of annealed $\mathrm{Al}_{2} \mathrm{O}_{3} / \mathrm{OTS}$ film. Scale bar is $50 \mathrm{~nm}$ for both images. 


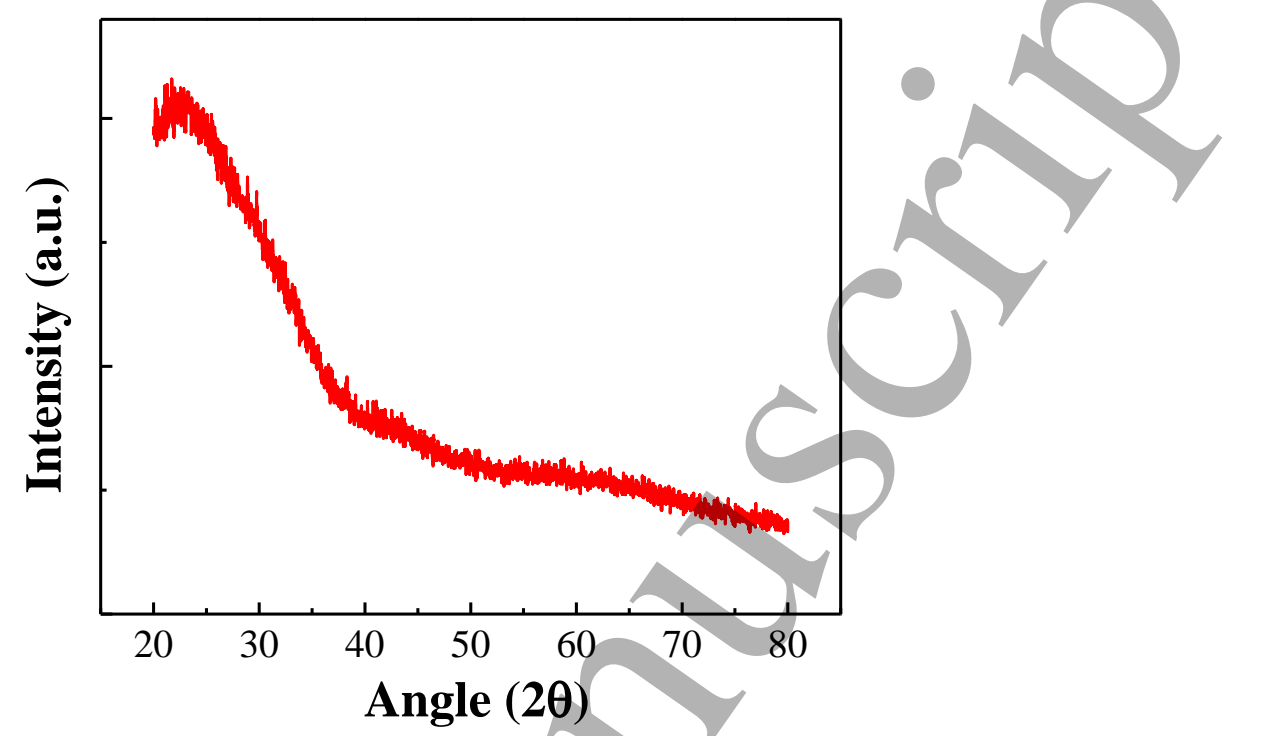

Figure S3. XRD spectrum of the annealed, anodized $\mathrm{Al}_{2} \mathrm{O}_{3}$ film showing the amorphous nature.

(a)

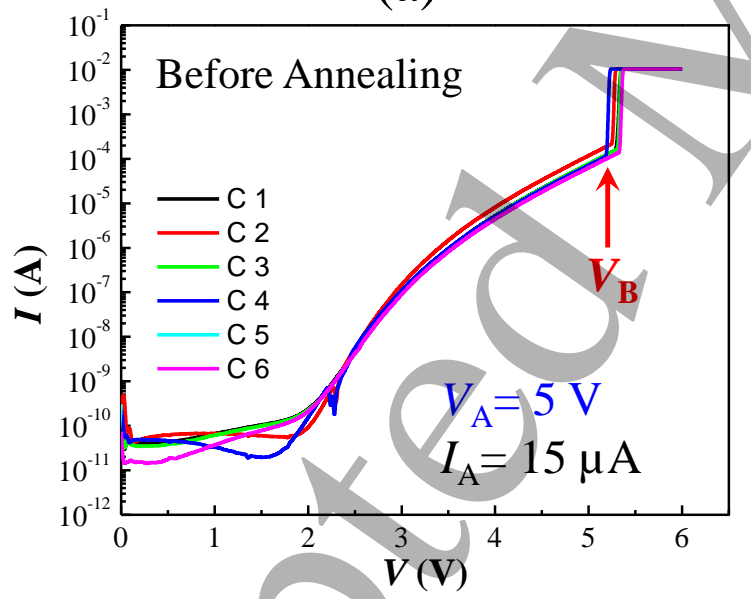

(b)

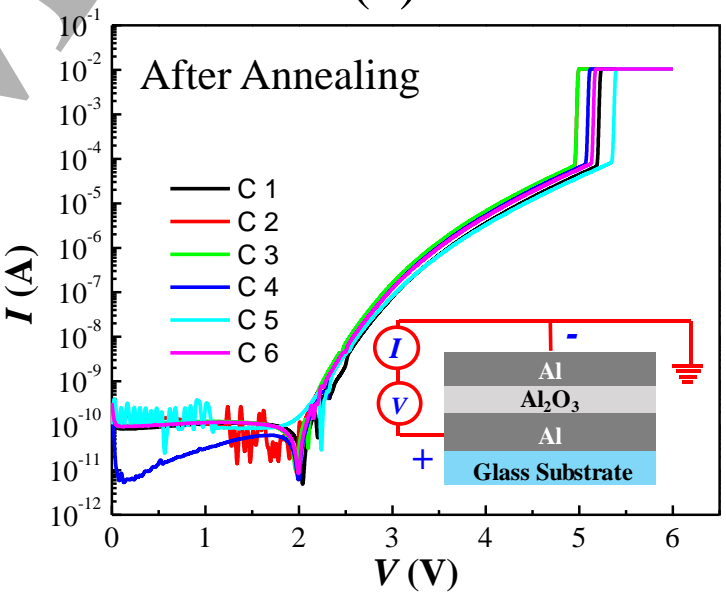

Figure S4. Breakdown voltage $\left(V_{\mathrm{B}}\right)$ measurements of six randomly chosen $\mathrm{Al} / \mathrm{Al}_{2} \mathrm{O}_{3} / \mathrm{Al} \mathrm{MIM}$ capacitors (C 1 to $\mathrm{C}$ 6) fabricated on the same glass substrate using citric acid as the electrolyte, (a) before and (b) after annealing. The anodization voltage $\left(V_{A}\right)$ and the anodization current $\left(I_{A}\right)$ were $5 \mathrm{~V}$ and $15 \mu \mathrm{A}$, respectively. The arrow in (a) indicates the estimated value of the breakdown voltage $\left(V_{\mathrm{B}}\right)$. Inset of (b) shows a schematic structure of the fabricated MIM capacitors used for the measurements. 